\title{
PERSEPSI PEJALAN KAKI TERHADAP TROTOAR DI LAPANGAN MERDEKA KOTA MEDAN
}

\author{
Johan Oberlyn Simanjuntak ${ }^{1}$, Tiurma Elita Saragi ${ }^{2}$, \\ Nurvita Insani M. Simanjuntak ${ }^{3}$, Titusman Berkat Laoli ${ }^{4}$ \\ Fakultas Teknik Universitas HKBP Nommensen, Medan \\ Email: oberlyn.simanjuntak@yahoo.co.id ${ }^{1}$, saragih_27@yahoo.com ${ }^{2}$, \\ nurvitainsani@gmail.com ${ }^{3}$, titusmanberkatlaoli@gmail.com ${ }^{4}$
}

\begin{abstract}
Merdeka Square is one of the icons of Medan City which is continously visited by communities of Medan City or immigrant communities because Medan City is the capital of North Sumatera Province with a high complexity of activities in it. Improvements to the road transportation system facilities especially sidewalk facilites are important because the purpose of implementing sidewalks was as a special pedestrian lane with security and safety guarantees against traffic accidents.

This study aims to look at people's perceptions as the main users of sidewalk facilities so that they can encourage people to carry out walking activities as a basic moda of transportation.

This research was conducted with a quantitative approach with accidental sampling method, namely primary data is the result of direct interviews in the field to the public using sidewalk facilities at Merdeka Square, Medan City.

Based on the result of the analysis conducted on the results of the interview, it was found that the community as users of the sidewalks were not satisfied with the existing sidewalks facilities. This study aims to provide input in order to improve sidewalk facilities that provide comfort and safety values for pedestrians in order to encourage and increase the number of pedestrians, especially at Merdeka Square, Medan City.
\end{abstract}

\section{Keywords : Merdeka Square, Sidewalk, Perception}

\section{PENDAHULUAN}

Hampir seluruh perjalanan manusia dilakukan berawalan dan berakhir dengan berjalan kaki. Berjalan kaki merupakan moda transportasi dasar yang berkaitan langsung dengan tatanan kehidupan masyarakat. Dengan demikian dalam mewujudkan keselamatan transportasi maka pembenahan terhadap fasilitas pendukung sistem transportasi jalan raya khususnya fasilitas pejalan kaki menjadi sorotan penting. Berdasarkan Pedoman Perencanaan Teknis Fasilitas Pejalan Kaki PD 03-2017-B (2017) fasilitas utama pejalan kaki terdiri atas jalur pejalan kaki (trotoar) dan penyeberangan yaitu penyeberangan sebidang dan penyeberangan tidak sebidang overpass (jembatan) dan underpass (terowongan). Penyelenggaraan trotoar berfungsi sebagai jalur khusus yang digunakan pejalan kaki yang 
bersebelahan langsung dengan jalur lalu lintas dengan adanya jaminan keamanan dan keselamatan terhadap resiko kecelakaan jalan lalu lintas.

Penelitian ini bertujuan untuk mengukur kepuasan pejalan kaki sebagai pengguna fasilitas trotoar di Lapangan Merdeka Kota Medan yang merupakan salah satu icon Kota Medan dimana lokasi ini merupakan tempat yang ramai dikunjungi oleh masyarakat. Elemen trotoar yang ditinjau pada penelitian ini berupa kondisi fisik trotoar, keamanan, kenyamanan, fasilitas pendukung, keberadaan elemen pemisah, nilai estetika, kondisi jalur trotoar, keberadaan lampu penerang, keberadaan marka untuk disabilitas, ketersediaan tempat duduk dan lebar jalur trotoar (Harvizan, 2019) ${ }^{2}$.

\section{TINJAUAN PUSTAKA}

\section{PEJALAN KAKI}

Dalam Pedoman Perencanaan Teknis Fasiltias Pejalan Kaki PD 03-2017-B (2017) yang dikeluarkan oleh Kementerian Pekerjaan Umum dan Perumahan Rakyat menyebutkan bahwa pejalan kaki merupakan bagian dari transportasi jalan raya yaitu setiap orang yang berjalan pada ruang lalu lintas baik dengan maupun tanpa alat bantu. Selain itu pejalan kaki dengan kebutuhan khusus yaitu orang yang dengan keterbatasan kemampuan yang dapat berarti para penyandang cacat (disabilitas), lanjut usia, ibu hamil maupun anak-anak.

\section{JALUR PEJALAN KAKI}

\section{A. Perencanaan Fasilitas Pejalan Kaki}

Menurut Pedoman Perencanaan Teknis Fasiltias Pejalan Kaki PD 03-2017-B (2017) ${ }^{3}$, dalam perencanaan fasilitas pejalan kaki harus memenuhi beberapa prinsip umum sebagai berikut :

1. Fasilitas pejalan kaki harus memenuhi aspek keterpaduan sistem yaitu meliputi penataan lingkungan, sistem transportasi dan aksesibilitas antar kawasan.

2. Fasilitas pejalan kaki harus memenuhi aspek kontinuitas, yaitu menghubungkan antara tempat asal ke tempat tujuan dan sebaliknya.

3. Fasilitas pejalan kaki harus memenuhi aspek keselamatan, keamanan dan kenyamanan. 
4. Fasilitas pejalan kaki harus memenuhi aspek aksesibilitas, dimana fasilitas yang direncanakan harus dapat diakses oleh seluruh pengguna, termasuk oleh pengguna dengan berbagai keterbatasan fisik.

Selain itu prinsip umum dalam perencanaan teknis fasilitas pejalan kaki harus memenuhi kriteria pemenuhan kebutuhan kapasitas, memenuhi ketentuan kontinuitas dan memenuhi persyaratan teknis aksesibilitas bagi semua pengguna termasuk pejalan kaki berkebutuhan khusus serta memilih konstruksi atau bahan yang memenuhi syarat keamanan dan relatif mudah dalam pemeliharaannya.

\section{Fasilitas Pendukung Jalur Pejalan Kaki}

Adapun fasilitas pendukung yang diperlukan dalam perencanaan jalur pejalan kaki berdasarkan Pedoman Perencanaan Teknis Fasiltias Pejalan Kaki PD 03-2017-B (2017) ${ }^{3}$ adalah sebagai berikut :

1. Rambu dan marka. Marka jalan merupakan piranti pengingat kepada pengemudi untuk berhati-hati dan bila diperlukan berhenti pada lokasi yang tepat untuk memberikan kesempatan pada pejalan kaki sedangkan rambu diletakkan pada jalur fasilitas, pada titik interaksi sosial, pada jalur dengan arus orang padat dengan besaran sesuai kebutuhan.

2. Pengendali kecepatan. Pengendali kecapatan adalah fasilitas untuk memaksa pengendara menurunkan kecepatan kendaraan saat mendekati fasilitas penyeberangan atau lokasi tertentu.

3. Lapak tunggu. Lapak tunggu adalah fasilitas untuk berhenti sementara pejalan kaki dalam melakukan penyeberangan.

4. Lampu penerangan fasilitas pejalan kaki. Lampu penerangan fasilitas pejalan kaki bertujuan untuk memberikan pencahayaan pada malam hari agar area fasilitas pejalan kaki dapat lebih aman dan nyaman.

5. Pagar pengaman. Pagar pengaman ditempatkan pada titik tertentu yang berbahaya dan memerlukan perlindungan.

6. Pelindung/peneduh. Jenis pelindung/peneduh disesuaikan dengan fasilitas pejalan kaki yang berupa pohon pelindung, atap dan lainnya. 
7. Jalur hijau. Jalur hijau diletakkan pada jalur fasilitas.

8. Tempat duduk. Penempatan tempat duduk pada fasilitas pejalan kaki dimaksudkan untuk meningkatkan kenyamanan pejalan kaki. Tempat duduk diletakkan pada jalur fasilitas dan tidak boleh mengganggu pergerakan pejalan kaki.

9. Tempat sampah.

10. Halte/ tempat pemberhentian bus. Halte bus diletakkan pada jalur fasilitas sehingga tidak mengurangi lebar efektif jalur pejalan kaki.

11. Drainase. Drainase terletak berdampingan atau di bawah fasilitas pejalan kaki. Drainase berfungsi sebagai penampung dan jalur aliran air pada fasilitas pejalan kaki.

12. Bolar. Pemasangan bolar dimaksudkan agar kendaraan bermotor tidak masuk ke fasilitas pejalan kaki sehingga pejalan kaki merasa aman dan nyaman bergerak.

\section{B. TROTOAR}

Berdasarkan Petunjuk Perencanaan Trotoar No.007/BNKT/1990 (1990) ${ }^{1}$ yang ditetapkan oleh Direktorat Jenderal Bina Marga Direktorat Pembinaan Jalan Kota, trotoar adalah jalur pejalan kaki yang terletak di daerah manfaat jalan, diberi lapis permukaan, diberi elevasi lebih tinggi dari permukaan perkerasan jalan, dan pada umumnya sejajar dengan jalur lalu lintas kendaraan. Trotoar berfungsi untuk memberikan pelayanan kepada pejalan kaki sehingga dapat meningkatkan kelancaran, keamanan dan kenyamanan pejalan kaki tersebut.

Lebar trotoar berdasarkan lokasi perencanaan trotoar disusun menurut Keputusan Menteri Perhubungan No. KM 65 Tahun 1993 tentang Fasilitas Pendukung Kegiatan Lalu Lintas dan Angkutan Jalan ${ }^{4}$ ditunjukkan pada Tabel 1.

Tabel 1. Lebar Trotoar Berdasarkan Lokasi ${ }^{4}$

\begin{tabular}{|c|l|c|}
\hline No. & \multicolumn{1}{|c|}{ Lokasi Trotoar } & Lebar Trotoar Minimum \\
\hline 1 & Jalan di daerah pertokoan atau kaki lima & 4 meter \\
\hline 2 & Di wilayah perkantoran utama & 3 meter \\
\hline 3 & Di wilayah industri : & 3 meter \\
& $\begin{array}{l}\text { a. Pada jalan primer } \\
\text { b. Pada jalan akses }\end{array}$ & 2 meter \\
\hline 4 & Di wilayah permukiman : & 2,75 meter \\
& a. Pada jalan primer & \\
\hline
\end{tabular}




\begin{tabular}{|l|l|l|}
\hline & b. Pada jalan akses & 2 meter \\
\hline
\end{tabular}

Sumber : Keputusan Menteri Perhubungan No. KM 65 Tahun 1993 (1993)

Sedangkan lebar trotoar berdasarkan jumlah pejalan kaki menurut Keputusan Menteri Perhubungan No. KM 65 Tahun 1993 tentang Fasilitas Pendukung Kegiatan Lalu Lintas dan Angkutan Jalan ${ }^{4}$ dijelaskan pada Tabel 2.

Tabel 2. Lebar Trotoar Berdasarkan Jumlah Pejalan Kaki ${ }^{4}$

\begin{tabular}{|c|c|c|}
\hline No. & $\begin{array}{c}\text { Jumlah Pejalan Kaki } \\
\text { (orang/detik/meter) }\end{array}$ & $\begin{array}{c}\text { Lebar Trotoar } \\
\text { (meter) }\end{array}$ \\
\hline 1 & 6 orang & $2,30-5,00$ \\
\hline 2 & 3 orang & $1,50-2,30$ \\
\hline 3 & 2 orang & $0,90-1,50$ \\
\hline 4 & 1 orang & $0,60-0,90$ \\
\hline
\end{tabular}

Sumber : Keputusan Menteri Perhubungan No. KM 65 Tahun 1993 (1993)

Untuk mengukur efektivitas trotoar digunakan tingkat pelayanan berdasarkan Petunjuk Perencanaan Trotoar No.007/BKNT/1990 (1990) yang dijelaskan pada Tabel 3.

Tabel 3. Tingkat Pelayanan Trotoar ${ }^{1}$

\begin{tabular}{|c|c|c|}
\hline Tingkat Pelayanan & $\begin{array}{c}\text { Modul } \\
\left(\mathbf{m}^{\mathbf{2}} \text { /orang) }\right.\end{array}$ & $\begin{array}{c}\text { Volume } \\
\text { (orang/meter/menit) }\end{array}$ \\
\hline A & $\geq 3,25$ & $\leq 23$ \\
\hline B & $2,30-3,25$ & $23-33$ \\
\hline C & $1,40-2,30$ & $33-50$ \\
\hline D & $0,90-1,40$ & $50-66$ \\
\hline E & $0,45-0,90$ & $66-82$ \\
\hline F & $\leq 0,45$ & $\geq 82$ \\
\hline
\end{tabular}

Sumber : Petunjuk Perencanaan Trotoar No. 007/BNKT/1990 (1990)

\section{METODE PENELITIAN}

Metode penelitian yang digunakan dalam penelitian ini adalah dengan pendekatan kuantitatif yang didasarkan atas persepsi pengguna trotoar Lapangan Merdeka Kota Medan. Data yang digunakan dalam penelitian didapatkan dengan menggunakan accidental sampling dengan cara mengumpulkan responden yaitu pejalan kaki yang secara kebetulan dijumpai pada kawasan Lapangan Merdeka Kota Medan. Responden diminta melakukan pengisian kuisioner yang telah dibentuk sebelumnya yang bertujuan untuk dapat secara langsung memberikan jawaban atas pengalaman menggunakan trotoar Lapangan Merdeka Kota Medan. 
Dalam penelitian ini, data yang digunakan dibagi menjadi dua (2) bagian yaitu data primer berupa hasil pengisian kuisioner)responden yaitu pejalan kaki serta data sekunder yaitu studi literatur yang dilakukan terhadap pedoman, tata aturan ataupun perundang-undangan yang mengatur tentang pejalan kaki di Indonesia.

Kuisioner yang dibentuk guna mendapatkan data primer menggunakan Likert Scale. Menurut Sugiyono (2018) likert scale atau skala likert adalah skala yang digunakan untuk mengukur sikap, pendapat dan persepsi seseorang atau kelompok tentang fenomena sosial. Dalam hal ini kuisioner dibentuk dengan mengajukan pertanyaan dengan alternatif 5 skala alternatif jawaban yaitu $1=$ sangat tidak puas; $2=$ tidak puas; $3=$ kurang puas; $4=$ puas dan 5 = sangat puas. Selanjutnya data yang didapatkan akan dianalisis menggunakan analisis deskriptif untuk memperoleh tingkat kepuasan pejalan kaki pada trotoar Lapangan Merdeka Kota Medan.

Sebagai pendukung, lokasi penelitian ditentukan yaitu seluruh bagian trotoar Lapangan Merdeka Kota. Untuk lebih dapat memahami lokasi penelitian, maka peta lokasi dan zona penelitian ditunjukkan pada Gambar 1.

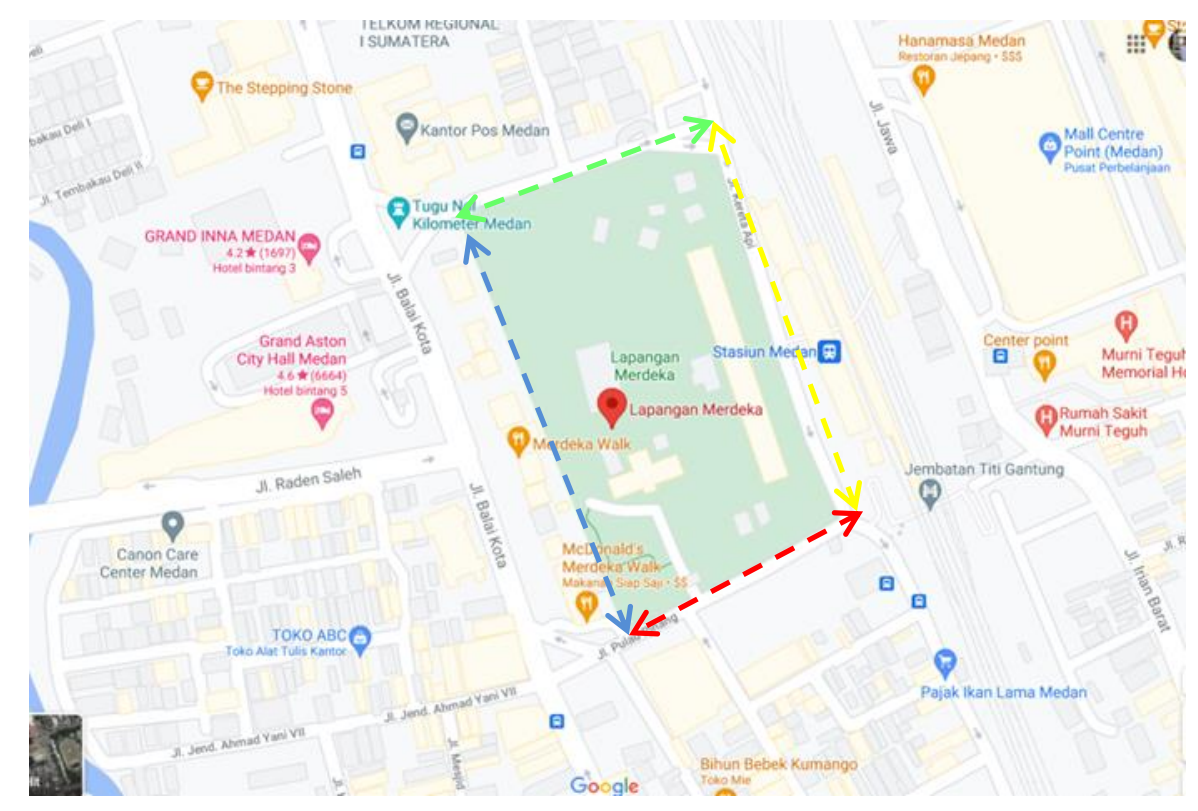

Gambar 1. Peta dan Zona Penelitian

Sumber : Google Maps (2021) 
Keterangan :

$<-->\quad=\quad$ Pintu masuk 1 (Jalan Balai Kota) / Zona A

$<--\rightarrow \quad=\quad$ Pintu masuk 2 (Jalan Pulau Pinang) $/$ Zona B

$=\quad$ Pintu masuk 3 (Jalan Kereta Api) / Zona C

$<-->\quad=\quad$ Pintu masuk 4 (Jalan Bukit Barisan) $/$ Zona $\mathrm{D}$

\section{ANALISIS DAN HASIL \\ DATA RESPONDEN}

Data primer yang didapatkan dalam penelitian ini berupa jawaban atas kuisioner yang telah dibagikan acak kepada sejumlah pejalan kaki sebagai pengguna utama fasilitas trotoar Lapangan Kota Medan. Berdasarkan survei yang dilakukan di lapangan maka didapatkan jawaban atas 720 responden. Data sosiodemografi responden ditunjukkan pada Gambar 2 dan Gambar 3.

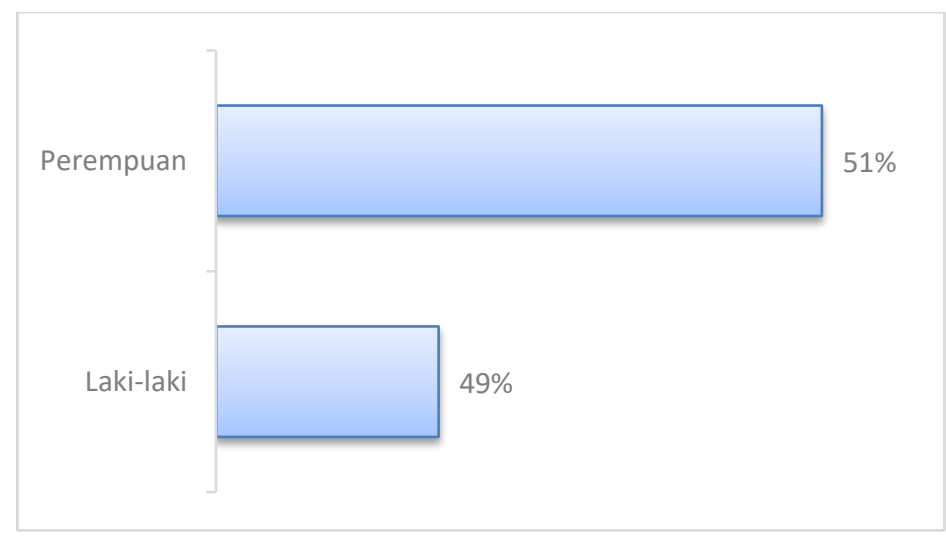

\section{Gambar 2. Grafik Persentase Responden Berdasarkan Jenis Kelamin}

Sumber : Hasil penelitian (2021) 
Jurnal Visi Eksakta (JVIEKS)

Vol.2, No.2, Juli 2021, pp. 129-140

https://ejournal.uhn.ac.id/index.php/eksakta/

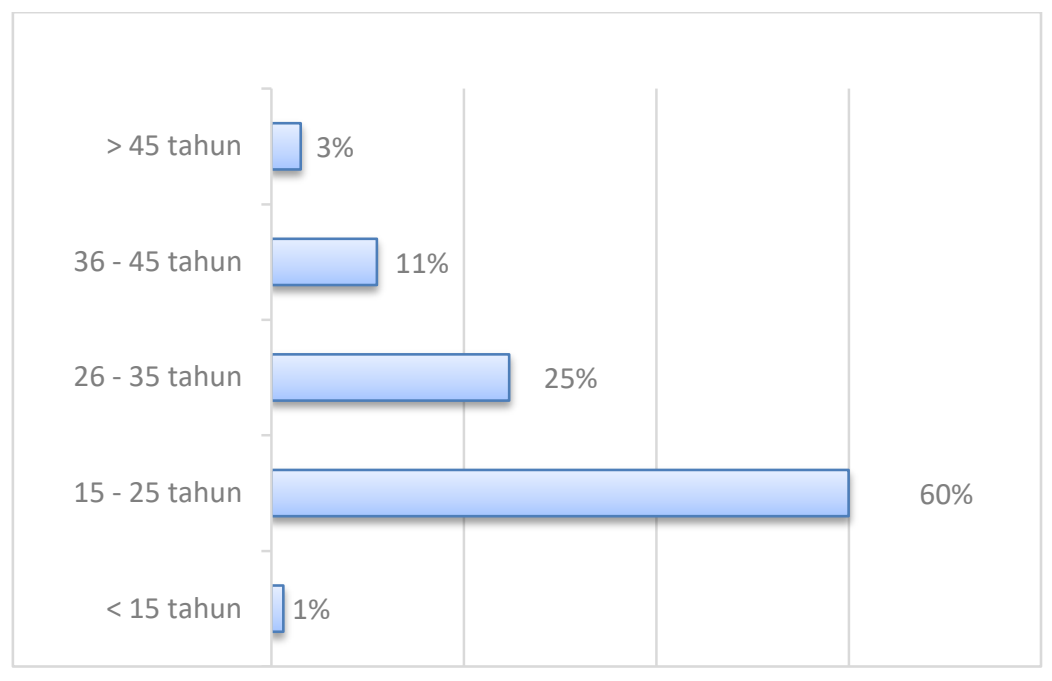

Gambar 3. Grafik Persentase Responden Berdasarkan Rentang Usia Sumber : Hasil penelitian (2021)

Sedangkan berdasarkan asal tujuan perjalanan responden digambarkan pada Gambar 4-dan Gambar 5.

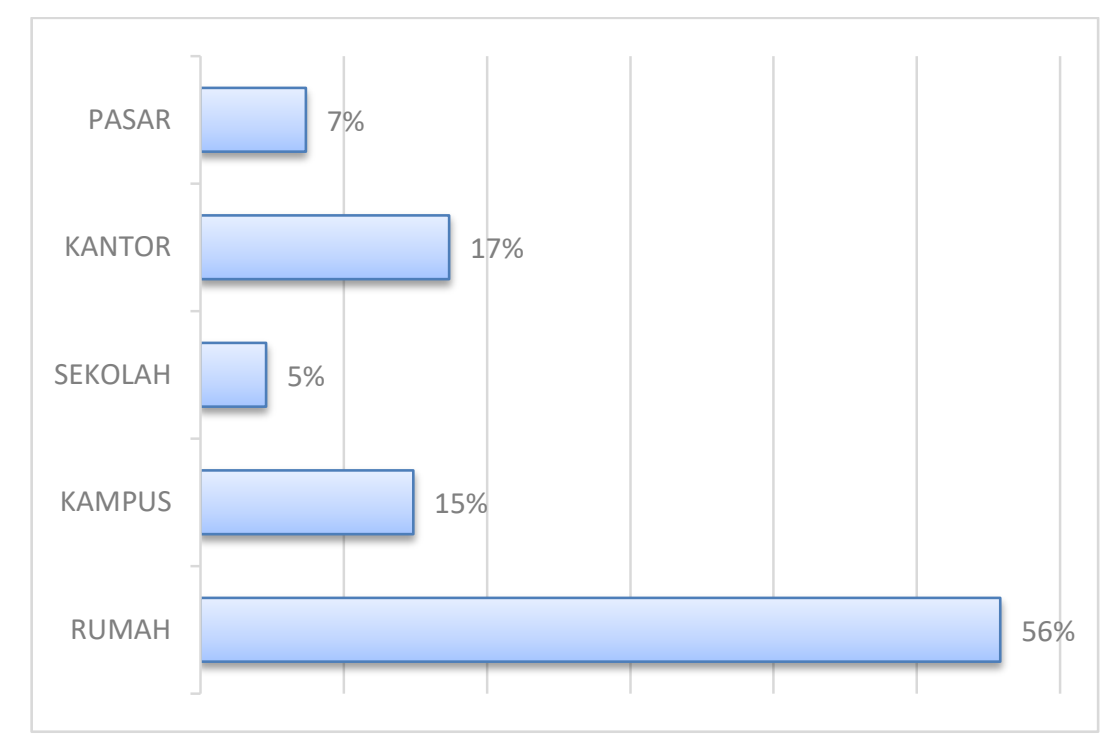

\section{Gambar 4. Grafik Persentase Responden Berdasarkan Asal Perjalanan (Origin)}

Sumber : Hasil penelitian (2021) 


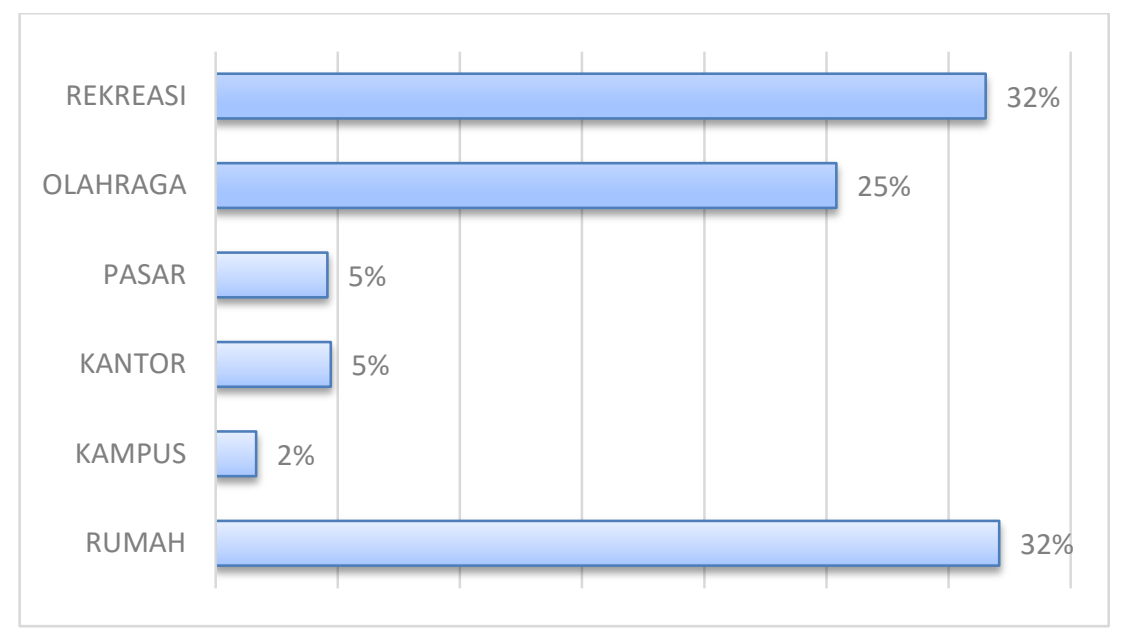

\section{Gambar 5. Grafik Persentase Responden Berdasarkan Tujuan Perjalanan (Destination) \\ Sumber : Hasil penelitian (2021)}

Berdasarkan data Gambar 3 (disimpulkan) bahwa untuk maksud asal perjalanan (origin) dari 720 responden, jumlah terbesar adalah berasal dari rumah yaitu 56\%, sedangkan asal perjalanan lainnya adalah berasal dari kantor, kampus / sekolah dan pasar. Hal ini menunjukkan bahwa responden yang menggunakan trotoar merupakan jalan menuju tujuan utama ataupun sebagai tempat untuk persinggahan dari perjalanan responden di Lapangan Merdeka. Sedangkan berdasarkan Gambar 4 memberi kesimpulan bahwa tujuan perjalanan (destination) dari sejumlah responden adalah rumah ataupun untuk rekreasi. Hal ini menunjukkan bahwa Lapangan Merdeka adalah sebagai tempat persinggahan responden yang akan menuju tujuan perjalanan akhir. Berdasarkan data Gambar 5 di atas juga diketahui bahwa Lapangan Merdeka Kota Medan juga merupakan sarana olahraga. Hal ini ditunjukkan dari tujuan perjalanan (destination) dari 720 responden adalah untuk olahraga yang memang pada umumnya Lapangan Merdeka Kota Medan khususnya bagian trotoar digunakan sebagai tempat berolahraga yaitu berjalan kaki yaitu sebesar $25 \%$.

\section{A. PERSEPSI RESPONDEN}

Data survei di lapangan yang berasal dari jawaban responden terhadap kuisioner maka persepsi pejalan kaki terhadap trotoar yang ada di Lapangan Merdeka Kota Medan dijabarkan dalam Tabel 4. 
Tabel 4. Persentase Persepsi Responden

\begin{tabular}{|l|c|c|c|c|c|}
\hline \multirow{2}{*}{\multicolumn{1}{c|}{ Item Analisis }} & \multicolumn{5}{c|}{ Skala Penilaian } \\
\cline { 2 - 6 } & $\begin{array}{c}\text { Sangat } \\
\text { tidak } \\
\text { puas }\end{array}$ & $\begin{array}{c}\text { Tidak } \\
\text { puas }\end{array}$ & $\begin{array}{c}\text { Kurang } \\
\text { puas }\end{array}$ & Puas & $\begin{array}{c}\text { Sangat } \\
\text { puas }\end{array}$ \\
\hline Fasilitas trotoar & $0 \%$ & $15 \%$ & $\mathbf{3 2 \%}$ & $29 \%$ & $24 \%$ \\
\hline Keamanan & $0 \%$ & $0 \%$ & $\mathbf{3 7 \%}$ & $30 \%$ & $34 \%$ \\
\hline Kenyamanan & $0 \%$ & $0 \%$ & $31 \%$ & $34 \%$ & $\mathbf{3 5 \%}$ \\
\hline Keberadaan elemen pemisah jalur & $0 \%$ & $1 \%$ & $28 \%$ & $29 \%$ & $\mathbf{4 2 \%}$ \\
\hline Nilai estetika & $0 \%$ & $1 \%$ & $\mathbf{3 4 \%}$ & $33 \%$ & $32 \%$ \\
\hline Kondisi jalur trotoar & $0 \%$ & $1 \%$ & $\mathbf{3 6 \%}$ & $34 \%$ & $29 \%$ \\
\hline Keberadaan lampu penerang & $0 \%$ & $5 \%$ & $\mathbf{3 6 \%}$ & $30 \%$ & $29 \%$ \\
\hline $\begin{array}{l}\text { Keberadaan marka untuk } \\
\text { masyarakat disabilitas }\end{array}$ & $0 \%$ & $\mathbf{3 6 \%}$ & $35 \%$ & $28 \%$ & $2 \%$ \\
\hline Ketersediaan tempat duduk & $0 \%$ & $0 \%$ & $\mathbf{3 5 \%}$ & $26 \%$ & $40 \%$ \\
\hline Lebar trotoar & $0 \%$ & $1 \%$ & $23 \%$ & $\mathbf{4 1 \%}$ & $36 \%$ \\
\hline
\end{tabular}

Sumber : Hasil penelitian (2021)

Dari data Tabel 4 di atas dapat diketahui bahwa sejumlah $32 \%$ responden memutuskan kurang puas terhadap fasilitas trotoar; kemudian sejumlah $37 \%$ responden memutuskan kurang puas terhadap keamanan di sepanjang trotoar; selanjutnya sejumlah $35 \%$ responden merasakan sangat puas terhadap kenyamanan; berikutnya sejumlah $42 \%$ responden memutuskan sangat puas terhadap keberadaan elemen pemisah jalur; kemudian sejumlah; 34\% responden memutuskan kurang puas terhadap nilai estetika trotoar; selanjutnya sejumlah $36 \%$ responden memutuskan kurang puas terhadap kondisi jalur trotoar; lainnya sejumlah $36 \%$ responden memutuskan kurang puas terhadap keberadaan lampu penerang, dan terakhir sejumlah $35 \%$ responden memutuskan kurang puas terhadap keberadaan marka untuk masyarakat disabilitas yang ditunjukkan pada Gambar 4.
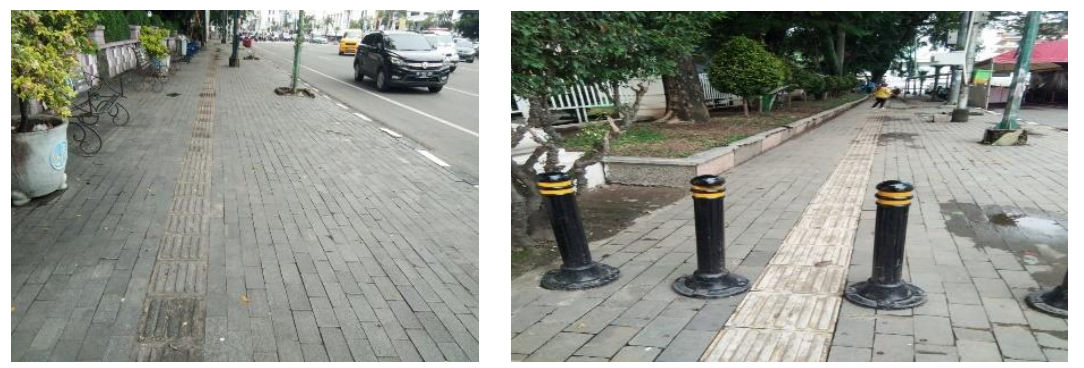

Gambar 6. Kondisi Keberadaan Marka Untuk Masyarakat Disabilitas

Sumber: Pengamatan langsung di lapangan (2021) 
Khusus terhadap ketersediaan tempat duduk ditemukan bahwa sejumlah $40 \%$ responden memutuskan sangat puas terhadap ketersediaan tempat duduk dan sejumlah $41 \%$ responden memutuskan puas terhadap lebar trotoar.

Dari semua persentase yang telah disebutkan di atas, survei tergolong normal untuk penelitian tentang persepsi pengguna trotoar di Lapangan Merdeka Kota Medan.

\section{KESIMPULAN}

Berdasarkan analisis yang telah dilakukan terhadap data survei langsung di lapangan kepada pengguna trotoar yaitu pejalan kaki maka dapat disimpulkan bahwa masyarakat Kota Medan khususnya para pejalan kaki merasakan bahwa trotoar yang ada di kawasan Lapangan Merdeka perlu mendapatkan perhatian tambahan. Dalam penyelenggaraanya trotoar harus dapat menjamin keamanan, kenyamanan, serta keselamatan dari pengguna trotoar itu sendiri. Keberadaan elemen pemisah jalur yang ada trotoar tampaknya juga menjadi perhatian pengguna karena dengan adanya pemisah lajur maka pengguna akan merasa aman terhadap kecelakaan yang mungkin terjadi antara pejalan dengan pengguna kendaraan bermotor. Pada fasilitas lainnya seperti kondisi jalur trotoar, lampu penerangan dan tempat duduk juga menjadi dominan yang menarik perhatian pengguna. Dikarenakan Lapangan Merdeka juga masih menjadi tujuan rekreasi ataupun olahraga dari masyarakat Kota Medan maka perbaikan atau pengadaan terhadap fasilitasfasilitas pendukung menjadi faktor yang dapat menarik jumlah pejalan kaki di kawasan ini. Akhirnya trotoar juga harus memenuhi aspek aksesibilitas dimana trotoar harus juga aman digunakan khususnya untuk masyarakat penyandang disabilitas. Maka untuk itu, perbaikan ataupun pengadaan terhadap marka/fasilitas lain khusus untuk disabilitas juga perlu ditingkat demi memberikan rasa aman terhadap seluruh pengguna trotoar.

\section{DAFTAR PUSTAKA}

Direktorat Jenderal Bina Marga. Direktorat Pembinaan Jalan Kota No.007/BNKT/1990. (1990). Petunjuk Perencanaan Trotoar, Jakarta.

Harvizan, Kevin. (2019)., Persepsi Kenyamanan Pejalan Kaki (Studi Kasus Koridor Pajak Ikan Lama Medan), Tugas Akhir. Departemen Arsitektur Fakultas Teknik Universitas Sumatera Utara. Medan. 
Jurnal Visi Eksakta (JVIEKS)

Vol.2, No.2, Juli 2021, pp. 129-140

https://ejournal.uhn.ac.id/index.php/eksakta/

罡佥 140

Kementerian Pekerjaan Umum dan Perumahan Rakyat Pd 03-2017-B. (2017)., Perencanaan Teknis Fasilitas Pejalan Kaki, Jakarta.

Keputusan Menteri Perhubungan No. KM 65 Tahun 1993. (1993)., Fasilitas Pendukung Kegiatan Lalu Lintas dan Angkutan Jalan, (1993). Jakarta.

Sugiyono. (2018)., Metode Penelitian Kuantitatif Kualitatif dan R\&D, Bandung: Alfabeta 